Bond University

Research Repository

\title{
Movement analysis of the golf swing
}

Hume, Patria A.; Keogh, J.

Published in:

Handbook of Human Motion

DOI:

10.1007/978-3-319-14418-4_137

Licence:

Other

Link to output in Bond University research repository.

Recommended citation(APA):

Hume, P. A., \& Keogh, J. (2018). Movement analysis of the golf swing. In B. Müller, S. I. Wolf, G-P.

Brüggemann, Z. Deng, A. S. Mclntosh, F. Miller, \& W. S. Selbie (Eds.), Handbook of Human Motion (Vol. 2, pp. 1755-1772). Springer. https://doi.org/10.1007/978-3-319-14418-4_137

\section{General rights}

Copyright and moral rights for the publications made accessible in the public portal are retained by the authors and/or other copyright owners and it is a condition of accessing publications that users recognise and abide by the legal requirements associated with these rights.

For more information, or if you believe that this document breaches copyright, please contact the Bond University research repository coordinator. 
Hume, P.A. and Keogh, J.

Movement analysis of the golf swing

Sports and Human Performance section of the Handbook of Human Motion.

Word count: 9185 (including abstract, text, index, cross references etc)

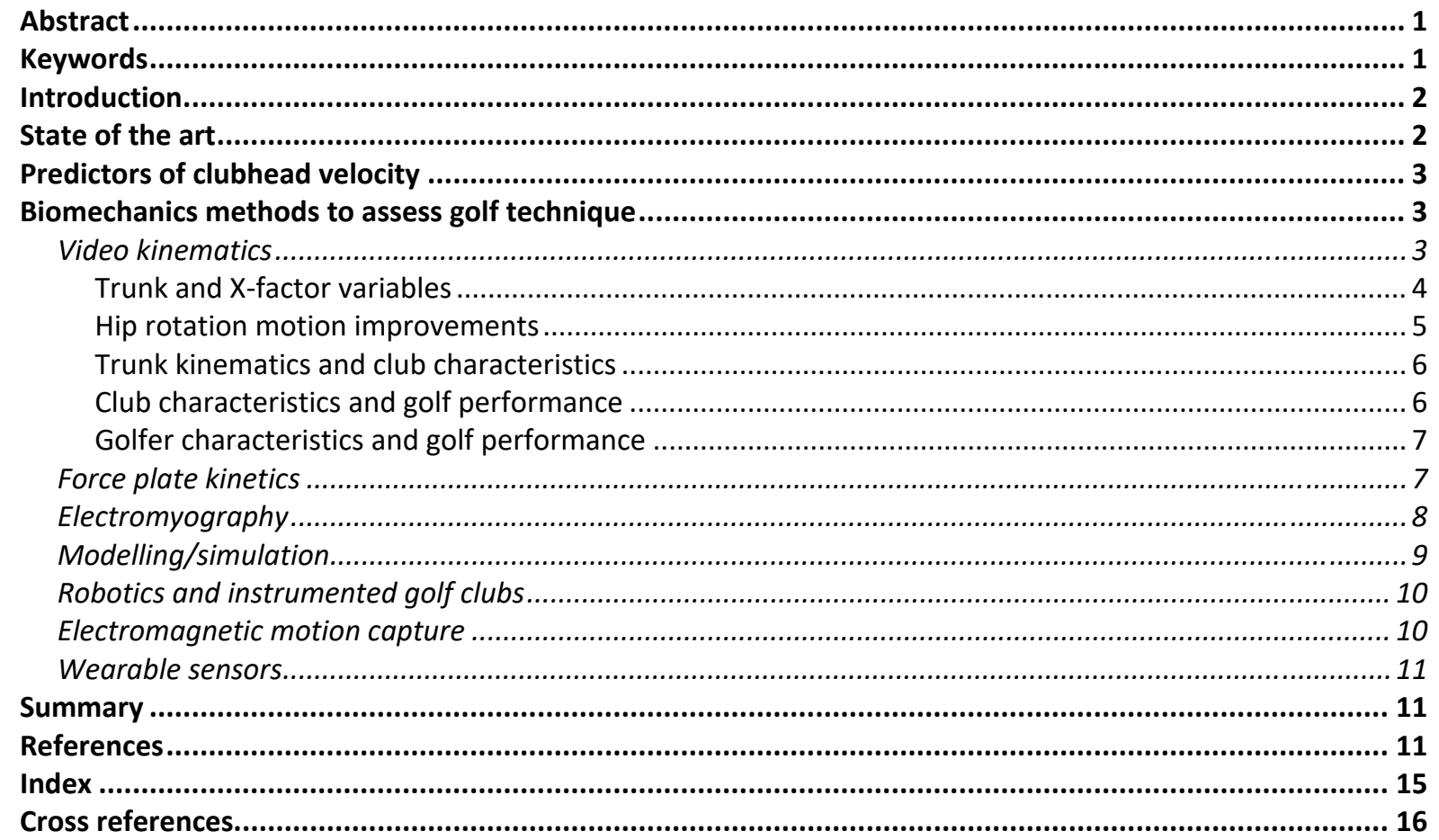

\begin{abstract}
Golf is popular world-wide. The complex and asymmetrical motion of golf swings, involving substantial forces and ranges of rotational movement, demands good technique if the player is to perform well while avoiding injury. Biomechanical analyses can help in maximising distance and accuracy of golf shots, and reducing injury risk, by providing qualitative and quantitative evidence of body angles, joint forces and muscle activity patterns. We highlight how lab based biomechanical studies of the golf swing using 3D videography, force, electromyography, modelling, and robots, have provided key information regarding the golf swing. With recent advances in technology such as isoinertial devices and wearable sensors, much of this knowledge can now be applied on the golf course. Sports biomechanists are now able to assess and provide relatively real-time feedback on golf swing performance. Golf performance outcome measures from a biomechanics perspective may be categorised as direct (ball displacement, shot accuracy) or indirect (clubhead velocity, clubface angle). The magnitude and direction of the linear clubhead velocity at impact is determined by the angular velocity of the clubhead during the swing and the length of the arm-club system. Golfers must develop a consistent fundamental swing pattern to secure these qualities. Proper proximal to distal sequencing of body rotations is important in the production of high clubhead velocities in the golf swing. The biomechanist must be able to measure golf performance technique and outcome variables reliably and with accuracy/sensitivity so feedback can be given to golfers and coaches on technique improvement.
\end{abstract}

\title{
Keywords
}

Golf, Clubhead velocity, Clubface angle, Shot accuracy, Kinematics, Kinetics, Feedback, Technique, Body kinematics, Joint angles, Segment velocities, Segmental sequencing, Inertial sensors, Telemetered sensors, Real-time feedback, Performance, Injury prevention. 


\section{Introduction}

Golf is popular world-wide, with people of all ages and genders participating in the sport. The aim of golf is to hit the golf ball into a small hole in as few shots as possible (Hume, Keogh, \& Reid, 2005). The techniques used for golf swings during driving, chipping and putting are key to performance and reduction of injury risk (Alexander \& Kern, 2005; Hellström, 2009). The complex and asymmetrical motion of the golf swing, involving substantial forces and ranges of rotational movement, demands good technique if the player is to avoid injuring their back, knees, elbows or wrists. For example, the golf swing generates forces and torques which tend to cause internal or external rotation of the tibia on the femur, which are resisted by the knee ligaments and menisci (Marshall \& McNair, 2013). Golfers may also develop medial epicondylosis, commonly known as 'golfer's elbow', because of the repetitive stress placed on the medial elbow soft tissues during pronation and wrist flexion (Hume, Reid, \& Edwards, 2006). Back pain and injuries are most frequently reported by golfers, and may be due to golf swing techniques that place an emphasis on restricting pelvic turn while increasing thorax rotation during the backswing to generate higher clubhead speeds at impact (Cole \& Grimshaw, 2016).

Biomechanical analyses can help in maximising distance and accuracy of golf shots, and reducing injury risk, by providing qualitative and quantitative evidence of body angles, joint forces and muscle activity patterns (Hume et al., 2005; Keogh \& Hume, 2012). Golfer movement has traditionally been assessed using two-dimensional (2D) or three-dimensional (3D) high-speed video or optoelectronic systems, to provide joint angles and segment velocities. Changes in technology have made it possible to measure and analyse golf movements in many ways and with new levels of precision. Advances in technology have seen the use of 3D force plates, pressure sensors, electromyography, computer simulations/modelling, inertial sensors, and instrumented golf clubs, for golf technique analyses. Ball velocity has been measured using a variety of ball launch systems (Bertram \& Guadagnoli, 2008; Wallace, Otto, \& Nevill, 2007), with the TrackMan system being one of the newer devices (Oliver, Horan, Evans, \& Keogh, 2016; Robertson, Burnett, Newton, \& al., 2012). TrackMan (www.trackman.dk) enables 3D golf ball trajectory and other animated data to be superimposed and compared relative to a target direction indicated in an image (by combining capture from a camera and radar ball direction).

Biomechanics methods have progressed over the years to enable measurement of golf techniques. Golf performance outcome measures from a biomechanics perspective may be categorised as direct (ball displacement, shot accuracy) or indirect (clubhead velocity, clubface angle) (Keogh \& Hume, 2012). The magnitude and direction of the linear clubhead velocity at impact is determined by the angular velocity of the clubhead during the swing and the length of the arm-club system. Golfers must develop a consistent fundamental swing pattern to secure these qualities (Kwon, 2010). Proper proximal to distal sequencing of body rotations is important in the production of high clubhead velocities in the golf swing. The biomechanist must be able to measure the golf performance technique and outcome variables reliably and with accuracy/sensitivity so feedback can be given to golfers and coaches on what needs to be the focus of technique improvement.

This chapter will focus on how biomechanics technologies are applied to improve performance and help prevent injury in golf.

\section{State of the art}

State of the art research evidence for use of instrumentation systems by sports biomechanists to assess technique and provide real-time feedback for golf performance is provided. 


\section{Predictors of clubhead velocity}

Golf swing clubhead velocity is associated with driving distance (Keogh et al., 2007). Low handicap performance is also associated with high clubhead velocities. For example, clubhead velocity has been correlated $(r=0.950)$ with golf handicap (clubhead velocity $=4.065-0.0214 \times \mathrm{hcp}$ ) for 45 male golfers (18-80 years, 2-27 hcp) (Fradkin, Sherman, \& Finch, 2004).

Biomechanical studies have improved our understanding of the variables that characterise a successful golf swing. Clubhead velocity has also traditionally been measured using laboratory based, 3D kinematic analysis systems (Egret, Vincent, Weber, Dujardin, \& Chollet, 2003; Horan, Evans, Morris, \& Kavanagh, 2010). More recently, clubhead velocity has been measured in the field using a Stalker Professional Sports radar gun (Applied Concepts, Plano, Texas, USA) operating at a frequency of $34.7 \mathrm{GHz}$ (Bradshaw et al., 2009; Keogh et al., 2009) or launch monitor systems such as the TrackMan (Oliver et al., 2016; Robertson et al., 2012). Clubhead velocity may be improved by increasing downswing amplitude (Delay, Nougier, Orliaguet, \& Coello, 1997), the sequential acceleration of body parts (Fletcher \& Hartwell, 2004) and shaft flexibility (Nesbit, 2005a). Individual golfer analysis of work, power, force and torque during golf swings may help to improve clubhead velocity (Nesbit, 2005b). Differences in reported clubhead velocities in studies are probably a result of the experience and skill of the golfers (novice, high and low handicap players, and professional golfers), the clubs used (drivers, irons, putters), as well as analysis methodologies. Researchers have reported correlations with clubhead velocity for golfer swing characteristics (Robinson, 1994) such as total work ( $r=0.431$ ) (Nesbit, 2005b), centre of pressure ( $r=0.46-0.58)$ (Ball \& Best, 2007a, 2007b) and ball impact locations higher on the club faces of drivers and 5-irons $(r=0.65)$ (Williams \& Sih, 2002).

Biomechanical studies have suggested that clubhead velocity can be improved by technique alterations such as reducing the radius path of the hands during the downswing, increasing wrist torque and/or range of motion, delaying wrist motion to late in the downswing, increasing downswing amplitude, improving sequential acceleration of body parts, improving weight transfer and utilising X-factor stretch (Keogh \& Hume, 2012). There is also the potential that a number of anthropometric (Kawashima, Kato, \& Miyazaki, 2003), flexibility, muscular strength and endurance characteristics may predict clubhead velocity in low- and high-handicap golfers (Keogh et al., 2009) and young elite players (Torres-Ronda, Delextrat, \& Gonzalez-Badillo, 2014).

When using biomechanics methods, researchers have attempted to identify predictors of performance using low handicap golfers. For example, a study of the relationship between swing technique characteristics and performance in golf driving for low handicap female golfers (Brown et al., 2011) reported there was no common driver swing technique for optimal performance. The recommendation for individual swing characteristic determination was based on analyses for the drive swings of 16 golfers using a 12-camera 3D motion capture system and a stereoscopic launch monitor. Three covariates (increased pelvis-thorax differential at the top of the backswing, increased pelvis translation during the backswing, and a decrease in absolute backswing time) were determinants of the variance in clubhead velocity (adjusted $r^{2}=0.965, P<0.05$ ). There were significant correlations between clubhead velocity and left-hand grip strength $(r=0.54, P<0.05)$, and sitting flexibility (clockwise: $r=0.522, \mathrm{P}<0.05$; counterclockwise: $r=0.711, \mathrm{P}<0.01$ ).

\section{Biomechanics methods to assess golf technique Video kinematics}

Golf coaches can use simple 2D video analysis to perform a range of qualitative and quantitative analyses of the golf swing in the field. Qualitative and quantitative assessments of relevant 
biomechanical variables such as the radius path of the hands during the downswing, range of motion and timing of wrist motion in the downswing, downswing amplitude, and sequential acceleration of body parts may be obtained from 2D analyses and help to provide feedback to golfers that will improve clubhead velocity and golf ball distance (Keogh \& Hume, 2012). However, the disadvantages are that the accuracy of the quantitative measurements is less than laboratory based 3D analyses, and usually data extraction is time intensive due to the manual nature of analysis, rather than semiautomatic analysis provided during laboratory based assessments.

Due to the highly complex multi-joint motions in golf, kinematic studies have focused on both the clubhead and various body segments (Egret et al., 2003; Evans, Refshauge, Adams, \& Barrett, 2008; Neal \& Wilson, 1985; Zheng, Barrentine, Fleisig, \& Andrews, 2008). As a total body sequential movement, the golf swing requires certain generic coordinative patterns to be effectively performed. Many studies have examined the nature of the coordination between the pelvis, torso and upper limb during the golf swing (Burden, Grimshaw, \& Wallace, 1998; Evans, Horan, Neal, Barrett, \& Mills, 2012; Horan, Evans, \& Kavanagh, 2011; Horan et al., 2010; Myers et al., 2008). Strong coupling between the thorax and pelvis (average $\mathrm{R}^{2}=0.92$ across all directions) is a method for simplifying the motor control strategy used during the downswing, and a way of ensuring consistent motor patterns (Horan \& Kavanagh, 2012). Three-dimensional data collected for 14 male professional golfers (age $27 \pm 8$ years, golf-playing experience $13.3 \pm 8$ years) using an optical motion analysis system showed the thorax segment had the highest peak velocities for the upper body during the downswing. The head and thorax showed a more variable coupling relationship (average $R^{2}=0.76$ across all directions).

Thorax and pelvis kinematics were shown to change during golf swings for male and female skilled golfers following the performance of 40 minutes of putting practice that challenged the trunk muscle endurance of the golfers (Horan, Evans, Morris, \& Kavanagh, 2014). The golfers were encouraged not to move from the spot, therefore maximising the time in which their trunk was inclined forward. Angular displacement at address, top of backswing and ball contact for the pelvis, thorax, and pelvis-thorax interaction were calculated, in addition to the magnitude of peak angular velocity and repeatability of continuous segment angular velocities. Female golfers had less pelvis and thorax anterior-posterior tilt at address, less thorax and thorax-pelvis axial rotation at top of backswing, and less pelvis and thorax axial rotation and pelvis lateral tilt at ball contact pre- to post-putting. Females had significantly lower thorax-pelvis lateral tilt peak angular velocity pre- to post-putting. Therefore, the endurance-based putting intervention affected females' thorax and pelvis orientation angles and velocities to a greater extent than males (Horan et al., 2014).

\section{Trunk and $X$-factor variables}

According to the kinetic link principle, rapid sequential stretching of the hip, trunk and upper limb muscles during the backswing would allow greater muscular forces and torques to be produced, with the ultimate result being an increase in clubhead velocity. The difference in hip and trunk angles at the top of the backswing was initially referred to as the X-factor (McLean, 1992) with the increase in this angle early in the downswing called the X-factor stretch. Evidence for the benefit of the X-factor and X-factor stretch in increasing clubhead velocity (Brown, Selbie, \& Wallace, 2013; Cheetham, Martin, Mottram, \& St Laurent, 2001; Cole \& Grimshaw, 2009; Evans et al., 2012; Kwon, Han, Como, Lee, \& Singhal, 2013; McTeigue, Lamb, Mottram, \& Pirozzolo, 1994) remains equivocal. The equivalence may reflect a range of methodological differences between studies. For example, $\mathrm{X}$-factor and trunk kinematic (flexion/extension, lateral bend, axial rotation) variables may be quite different when calculated by 2D compared to 3D methods (Smith, Roberts, Wallace, Pui, \& Forrester, 2016). Differences between 2D and 3D X-factor $\left(\sim 16^{\circ}\right)$ results can be explained by projection errors introduced to $2 \mathrm{D}$ analysis through trunk flexion $\left(-6.5 \pm 3.6^{\circ}\right)$ at the top of the backswing and trunk right-side lateral bend $\left(8.7 \pm 2.9^{\circ}\right)$ of the trunk and pelvis segments at impact. Therefore, a 3D 
method for kinematic data calculation would appear necessary to accurately analyse most aspects of the golf swing.

In a study examining the performance of 20 drives, eight high-handicap golfers (11-20 hcp) had greater hip rotation at the top of the backswing and reduced maximum X-factor compared with seven low-handicap golfers (0 - $10 \mathrm{hcp}$ ) (Cole \& Grimshaw, 2009). In a study of ten professional and five amateur male golfers (Meister et al., 2011), clubhead velocity at impact was correlated to Xfactor at impact $(r=0.94)$, peak X-factor $(r=0.90)$, peak upper-torso rotation $(r=0.90)$ and peak free moment per kilogram $(r=0.94)$. Downswing was initiated by reversal of pelvic rotation, followed by reversal of upper-torso rotation. Peak X-factor preceded peak free moment in all swings for all golfers, and occurred during initial downswing.

However, methodological considerations for the 3D measurement of the X-factor and lower trunk movement in golf continue to be debated (Brown et al., 2013; Cole \& Grimshaw, 2009; Joyce, Burnett, \& Ball, 2010; Kwon et al., 2013; Wheat, Vernon, \& Milner, 2007). There is currently no universal method of measuring rotational angles during the golf swing. Different marker placement methods and analysis models can result in different outcomes for X-factor.

A lateral bending/flexion-extension/axial rotation (ZYX) order of rotation was deemed to be the most suitable Cardanic sequence to use in the assessment of the X-factor and lower trunk movement in the golf swing in one study (Joyce et al., 2010). However, in an evaluation (Brown et al., 2013) of three common methods used to analyse the X-Factor there were significant differences for events during the swing. A twelve-camera 3D motion capture system captured driver swings of 19 golfers. Subject specific 3D biomechanical models were created with the position and orientation of each model estimated using a global optimisation algorithm. Data for each kinematic measure were derived as a times series for all three methods. Regression analysis of these data showed that whilst one method could be successfully mapped to another, the mappings between methods were subject-dependent. A consistent methodology considering the X-Factor from a joint angle approach was recommended for describing inter-segment kinematics during golf swings.

The validity of X-factor computation methods and whether direct relationships exist between Xfactor parameters and clubhead velocity has been examined in a group of skilled male golfers ( $n=18,-0.6 \pm 2.1 \mathrm{hcp}$ ) (Kwon et al., 2013). Five driver trials were captured from each golfer using an optical motion capture system $(250 \mathrm{~Hz})$. Two plane-based methods (conventional vs. functional swing plane-based) and one Cardan rotation-based method (relative orientation) were used to compute select X-factor (end of pelvis rotation, top of backswing, ball impact, and maximum), Xfactor stretch (stretch and maximum stretch), and X-factor velocity (ball impact and maximum) variables. The three computational methods generated significantly different $\mathrm{X}$-factor parameter values. The conventional method provided substantially larger $X$-factor values than the other methods in the untwisting phase, and the correlation analysis revealed that $\mathrm{X}$-factor variables were not directly related to maximum clubhead velocity. The meaningfulness of select $X$-factor parameters generated by the conventional method was deemed questionable (Kwon et al., 2013).

\section{Hip rotation motion improvements}

Appropriate pelvic rotations are important in producing an efficient strike on the ball so that the maximum amount of energy is transferred from the club to the ball. The smash factor has been defined as the ratio of club velocity before impact to ball velocity after impact (Lynn et al., 2013). The smash factor is one of the variables included in the TrackMan launch monitor outputs (http://trackmangolf.com/). There are differences in pelvic kinematics and ball flight determinants between golfers of different skill levels. Skilled golfers have greater pelvic accelerations and a larger 
time between peak pelvic velocity and ball contact (peak to impact time) then less skilled individuals (Lynn et al., 2013).

While flexibility has long been considered important for golfers, improving passive hip ROM may not be associated with increased hip rotation utilised during the golf swing. In a study of seven skilled male golfers between the ages of 18 and 40 years, dynamic kinematic hip rotation data were captured with a high-speed optoelectric 3D motion capture system during a golf swing. There were weak correlations between passive and dynamic range of rotation in lead and trail hips during the golf swings (Alderslade, Crous, \& Louw, 2015). Additionally, there was a lack of any significant between-group difference and hip internal or external rotation between lower and high handicap players; or any significant correlation between club head speed and these hip rotational measures (Keogh et al., 2009).

\section{Trunk kinematics and club characteristics}

Significant 3D trunk kinematic differences exist when using different clubs for golf swings. For example, multiple regression analyses with trunk and lower trunk flexion/extension and lower trunk axial rotation variables explained variance in clubhead velocity for a driver (33.7\%) and five-iron (66.7\%) in a study of 15 low-handicap male golfers ( $2.5 \pm 1.9 \mathrm{hcp}$ ) (Joyce, Burnett, Cochrane, \& Ball, 2013). A 10-camera motion capture system operating at $250 \mathrm{~Hz}$ collected player kinematics, and a real-time launch monitor collected clubhead velocity and ball velocity.

Kinematic factors that contribute to greater hitting distance when using the 5 iron club are greater hip joint movement and X-factor angle during the downswing, shoulder flexion and less left shoulder internal rotation in the backswing, greater extension angular velocity in both shoulders at early downswing, greater left shoulder adduction angular velocity at ball contact, and greater left elbow extension early in the downswing (Healy et al., 2011). Three-dimensional marker coordinate data were collected at $250 \mathrm{~Hz}$ to calculate joint kinematics, while a swing analyser measured club swing and ball launch characteristics for 30 male golfers in high or low ball launch velocity (high: $52.9 \pm 2.1 \mathrm{~m} \cdot \mathrm{s}-1$; low: $39.9 \pm 5.2 \mathrm{~m} \cdot \mathrm{s}-1$ ) groups.

Kinematics and clubhead velocity are different depending on the type of clubs used (e.g., driver, fiveiron, pitching-wedge). However, similar timing (movement time and proportion for each phase of the swing) may occur when using different clubs according to the results from a study of seven righthanded male golfers (Egret et al., 2003). Kinematic data during swings using three different clubs were collected with an optoelectronic system with five cameras operating at $50 \mathrm{~Hz}$. Low sampling systems (i.e. at $50 \mathrm{~Hz}$ ) may not be sufficient for such analyses when the driver is being used. Clubhead speed was measured using a swing made detector (Bell-Tronics, Ltd, Covington, USA).

\section{Club characteristics and golf performance}

Golf club shaft stiffness can affect ball launch conditions by altering clubhead speed and/or loft angle at ball impact (Worobets \& Stefanyshyn, 2012). Forty golfers hit 10 balls with each of five drivers varying in shaft stiffness from 'Ladies' to 'Extra-Stiff,' in a double-blind study design. The motions of three reflective markers attached to the clubhead were captured with a high-speed motion analysis system. At ball impact, shaft stiffness had a statistically significant influence on clubhead velocity for 27 subjects, on loft angle for 11 subjects, and on lie angle for all 40 subjects. No significant effect of shaft stiffness was observed on face angle, in to out path angle, or attack angle.

Shaft length affects golf driving performance (Kenny, Wallace, \& Otto, 2008). Clubhead and ball launch conditions and drive distance and accuracy were determined for seven golfers $(0.21 \pm 2.41$ hcp) who performed shots on a purpose-built practice hole using a range of drivers $(1.168 \mathrm{~m}$ and $1.270 \mathrm{~m})$. As shaft length increased initial ball velocity increased $(+1.8 \mathrm{~m} / \mathrm{s})$, and there was no 
decrease in accuracy. Ball launch conditions of spin components and launch angle remained unaffected by shaft length.

The effect of shaft stiffness on the dynamics of golf drives has been quantified (Betzler, Monk, Wallace, \& Otto, 2012). Twenty golfers performed swings with two clubs designed to differ only in shaft bending stiffness. Wrist kinematics and clubhead presentation to the ball were determined using optical motion capture systems in conjunction with a radar device for capturing ball speed, launch angle, and spin. The less stiff club increased clubhead $(0.45 \%)$ and ball speeds $(0.7 \%)$ as a result of a faster recovery of the lower flex shaft from lag to lead bending just before impact and an increase of $0.4 \%$ in angular velocity of the grip of the lower flex club at impact. Decreases in shaft stiffness led to more shaft bending at the transition from backswing to downswing. However, taking effect sizes into account, the changes in shaft stiffness in isolation did not have a meaningful effect on the measured parameters, for the type of shaft investigated.

A 3D optoreflective system operating at $400 \mathrm{~Hz}$ has been used to capture swings of 21 male golfers using their own drivers in an attempt to quantify 3D ball flight characteristics and their relationship to clubhead kinematics at impact. Club-head kinematics at impact (velocity, orientation, path, and centeredness) can explain a significant proportion (adjusted $r^{2}=0.71-0.82$ ) of early ball flight characteristics including resultant velocity, launch angle, side angle, back spin, and side spin even when generalized across individual clubs (Sweeney, Mills, Alderson, \& Elliott, 2013).

\section{Golfer characteristics and golf performance}

Studies comparing golfers of varying age, gender, ability and fitness may increase our understanding of the determinants of golf ball displacement and accuracy and provide golf coaches with additional information on how to coach a variety of clients. Several studies have reported gender-related differences in golf swing characteristics (Egret, Nicolle, Dujardin, Weber, \& Chollet, 2006; Horan et al., 2010; Zheng et al., 2008). Egret et al. (2006) reported that their five female golfers (20.4 \pm 4.2 years; $6.1 \pm 3.4 \mathrm{hcp}$ ) seemed to produce a wide swing with larger hip and shoulder joint rotation angles at the top of the backswing than their seven male golfers ( $23.1 \pm 2.9$ years; $6.6 \pm 1.7 \mathrm{hcp}$ ), and the male golfers flexed their left knee more during the backswing. However, neither of these significant gender-related differences in the kinematics of the golf swing showed any significant relationships with clubhead velocity. Horan et al. (2010) reported that 19 male skilled golfers (hcp $<4 ; 26 \pm 7$ years) had different lateral and anterior posterior pelvis tilt than their 19 female skilled golfers (hcp $<4 ; 25 \pm 7$ years). The results of these two studies suggest that what might be considered optimal swing characteristics for male golfers may not necessarily apply to female golfers. There been no studies that have directly compared the effect of age on golf swing technique.

Golf also provides opportunities for athletes with a disability. Kinetic and kinematic differences in the golf swing in one leg and two legs amputees has been examined for two males and one female golfers (professional or amateur levels) with different degrees of disability (Stastny et al., 2015). Each amputee golfer performed five golf swings with the iron 6 with 3D data recorded. There was a significant relationship between the level of amputation and a number of kinetic and kinematic variables such as the $\mathrm{X}$-factor and individual body angles. The fluency and similarity of the golf swing did not depend on the level of amputation. The most variable parameter was a weight-shift in all golfers. The takeaway and horizontal force angle depended on the level of amputation rather than individual technique.

\section{Force plate kinetics}

Using common biomechanical concepts, kinetic determinants of the golf swing include the kineticlink principle, angular impulse-momentum relationship, summation of forces (including ground reaction forces) and stretch-shorten cycle (Hume, et al., 2005). When a golfer wants to maximise the 
distance of their drives and long irons, relatively large ground reaction forces and joint torques would appear to be required (Barrentine, Fleisig, Johnson, \& Woolley, 1994; Worsfold, Smith, \& Dyson, 2008). During the golf swing, the reaction forces applied at the feet control translation and rotation of the body-club system. Skilled players $(n=12)$ using a 6 -iron regulated shot distance by scaling the magnitude of the resultant horizontal reaction force applied to each foot with minimal modifications in force direction (McNitt-Gray, Munaretto, Zaferiou, Requejo, \& Flashner, 2013). During each swing, reaction forces were measured using dual force plates $(1200 \mathrm{~Hz})$ and 3D kinematics were simultaneously captured $(110 \mathrm{~Hz})$.

Within-swing changes in ground reaction forces, often referred to as weight transfer, may help in optimising golf ball displacement (Ball \& Best, 2007a, 2007b; Jenkins, 2008). It has been advocated that during the backswing a greater proportion of the ground reaction forces be on the back foot, with transfer of the ground reaction forces onto the front foot during the downswing/acceleration phase. Elite golfers used weight transfer toward the target throughout the swing to provide extra energy to the ball (Gryc, Zahalka, Maly, Mala, \& Hrasky, 2015). Kinematics were collected using the 3D CODA Motion System, and weight transfer data were collected using two force plates.

\section{Electromyography}

Electromyography (EMG) studies support the view that skilled golf performance involves sequential muscle activation (McHardy \& Pollard, 2005), with different muscles becoming more active in varying phases (e.g. downswing) (Glazebrook, Curwin, Islam, Kozey, \& Stanish, 1994). Although the level of muscle activation depends on the swing phase, relatively high levels of hip and knee (Bechler, Jobe, Pink, Perry, \& Ruwe, 1995) and trunk (Watkins, Uppal, Perry, Pink, \& Dinsay, 1996) muscle activity are observed, with less activation of the muscles around the shoulder girdle/joints (Kao, Pink, Jobe, \& Perry, 1995).

Electromyography may also be used in conjunction of other data collection approaches to estimate internal forces during the golf swing. Four super VHS camcorders and two force plates were used to obtain 3D kinematics and kinetics of golf swings performed by five male collegiate golfers. Average EMG levels for different phases of golf swings were determined for activity of right and left rectus abdominis, external and internal obliques, erector spinae, and latissimus dorsi muscles. An EMGassisted optimization model was applied to compute the contact forces acting on the L4-L5. Mean peak compressive load at L4-L5 was over six times body weight during the downswing. Mean peak anterior and medial shear loads approached 1.6 and 0.6 BW during the follow-through phases. Average EMG levels of different muscles are highest in the acceleration and follow-through phases, suggesting a likely link between co-contractions of paraspinal muscles and lumbar spinal loads (Lim, Chow, \& Chae, 2012).

Myoelectric activity of the lumbar erector spinae and the external obliques was recorded via surface EMG, whilst 12 male golfers who experienced low back pain whilst playing or practicing golf, and 18 asymptomatic golfers, performed 20 drives (Cole \& Grimshaw, 2008). Low-handicap (0-12 hcp) low back pain golfers tended to demonstrate reduced lumbar erector spinae activity at the top of the backswing and at impact and greater external obliques activity throughout the swing than golfers without low back pain. The reduced erector spinae activity may be associated with a reduced capacity to protect the spine and its surrounding structures at the top of the backswing and at impact, where the torsional loads are high.

There are differences in muscle activity patterns between golfers of various standards such as more pronator teres muscle activity during the golf swing for professional and low handicap ( $<4 \mathrm{hcp}$ ) than amateur (10-20 hcp) golfers (Farber, Smith, Kvitne, Mohr, \& Shin, 2009). More consistent shoulder and wrist muscle activity patterns and temporal patterning of the different phases of chip shots have 
been reported for expert than novice golfers performing pitching wedge, 9-iron and 7-iron shots to targets located 20-m, 40-m and 60-m away (Abernethy, Neal, Moran, \& Parker, 1990).

\section{Modelling/simulation}

Simulation studies utilsing 2D three segment models with joint torque generators (Sprigings \& Mackenzie, 2002) or 3D full body models (Nesbit, 2005a) have demonstrated the important role of the wrist in the golf swing. These studies have shown that reducing the radius path of the hands during the downswing (Nesbit, 2005a), increasing wrist torque (Nesbit, 2005a; Sprigings \& Mackenzie, 2002), increasing wrist range of motion (Nesbit, 2005b) and delaying relative wrist motion to late in the downswing (Nesbit, 2005a) all increase clubhead velocity. Simulation studies have provided an insight into the role of the kinetic link principle in the golf swing (Nesbit, 2005a, 2005b; Sprigings \& Neal, 2000).

A 2D three-segment model comprising torso, left arm, and golf club was used to model the downward phase of the golf swing. Torque generators that adhered to the activation and forcevelocity properties of muscle were inserted at the proximal end of each segment. Separate simulations were performed, with the wrist joint generator enabled then disabled. Delaying the uncocking of the wrists to when the lead arm was about $30^{\circ}$ below the horizontal took advantage of the kinetic link principle resulting in a greater summation of angular velocities, and more linear clubhead velocity at ball impact and ball displacement (Sprigings \& Neal, 2000).

Work and power (energy) analyses of golf swings can provide a more comprehensive description of the downswing (Nesbit, 2005b). Two computer models were used to estimate the energy production, transfers, and conversions within the body and the golf club by employing standard methods of mechanics to calculate work of forces and torques, kinetic energies, strain energies, and power during the golf swing. The model of the golf club determined the energy transfers and conversions within the club during the downswing. The full-body computer model of the golfer determined the internal work produced at the body joints during the downswing. Four diverse amateur subjects were analysed and compared using these two models. The energy approach yielded new information on swing mechanics, determined the force and torque components that accelerated the club, illustrated which segments of the body produced work, determined the timing of internal work generation, measured swing efficiencies, calculated shaft energy storage and release, and proved that forces and range of motion were equally important in developing clubhead velocity.

An additional 3D kinematic and kinetic study of the golf swing (Nesbit, 2005a) performed by 84 male and one female amateur subjects of various skill levels was reported. The analysis was performed using a variable full-body computer model of a human coupled with a flexible model of a golf club. Data to drive the model were obtained from subject swings recorded using a multi-camera motion analysis system. Model output included club trajectories, golfer/club interaction forces and torques, work and power, and club deflections. The study further highlighted the importance of the wrists in generating clubhead velocity and orienting the club face as it approaches ball impact. The trajectory of the hands and the ability to do work were the factors most closely related to skill level.

Hand path and club angular trajectories were manipulated to increase clubhead velocity at impact for a further four golfers with diverse swing capabilities and styles (Nesbit \& McGinnis, 2014). A 2D dynamic model provided kinetic constrained optimization of the golf swing hub path. The manner of the modifications, the degree of velocity improvement, the amount of kinetic reduction, and the associated kinetic limitation quantities were subject-dependent. By artificially minimizing selected kinetic inputs within the optimization algorithm, it was possible to identify swing trajectory characteristics that indicated relative kinetic weaknesses of a golfer. 


\section{Robotics and instrumented golf clubs}

Putting proficiency is also a key determinant of golfing success. In a study of 10 single figure handicap golfers (Delphinus \& Sayers, 2012), proficient $(>79 \%)$ putters tended to move predominantly in the frontal plane (towards the target), while the non-proficient $(<79 \%)$ putters moved more sagittally. Golfers completed 18 putts $(2 \mathrm{~m})$ towards a cup in an indoor facility, with their linear movements of the centre of mass and head, and the angular movements of the pelvis and trunk recorded using 3D analysis at $100 \mathrm{~Hz}$ using a six-camera motion capture system.

Robots have been used to help learn golf putting (Reinkensmeyer \& Patton, 2009). TopSwing is a parallel robot developed by Sofea Software GmbH in Germany that provides trajectory training for golf swings (Kummel, Kramer, \& Gruber, 2014). Haptic guidance successfully changed the golf back swing technique for a group of healthy golf novice participants. This improvement in golf swing technique lasted for at least seven days after the training.

The TOMI ${ }^{\circledR}$ putting robot (Mackenzie \& Evans, 2010) was developed for measuring putting stroke kinematics (face angle, stroke path, putter speed, and impact spot at the moment of ball contact) has been found to be reliable and valid when assessed against a 3D high-speed camera system. All putts were executed from a distance of $4 \mathrm{~m}$ on a straight and flat synthetic putting surface.

The InPutter engineered putter is equipped with an inertial measurement unit, force sensitive resistors and heartbeat radio-frequency receiver compatible with Polar electrocardiogram transmitters. With a sample frequency of $100 \mathrm{~Hz}$, the device can be combined easily with other alternatives, such as cameras, to increase the range of applications and variables for further analysis. The InPutter has been validated experimentally using data collected from expert golfers (Couceiro, Dias, AraúJo, \& Pereira, 2015).

Sampling at a higher frequency of $1000 \mathrm{~Hz}$, the SmartSwing instrumented driver golf club (model LS300) (www.smartswinggolf.com/site/tic/science.html) was used in a project to develop an augmented video coaching system using qualitative analysis and post-production open source software (Bačić \& Hume, 2012). The machine learning diagnostic outputs were similar ( $89.5 \pm 2.6 \%)$ to those produced by the instrumented golf club (Bačić, 2012).

\section{Electromagnetic motion capture}

One of the major issues affecting the ecological validity of golf biomechanical research has been the difficulty in examining the biomechanics of the golf swing in realistic field conditions. However, with the development of new technologies, sports biomechanists are now able to quantify the 3D motion of golfers on the golf course, thereby allowing research to be conducted in this environment. The repeatability of 3D thorax and pelvis kinematics in the golf swing measured using a field-based electromagnetic motion capture (Evans et al., 2012) has been reported as suitable to assess swing kinematics for golfers in context-specific environments. Two golfers ( $\leq 14 \mathrm{hcp}$ ) performed five swings with each of two clubs (five-iron and driver) on consecutive days in indoor and outdoor locations.

Kinematic proximal-to-distal sequencing and speed-summation (successive increase in peak segment angular velocity) have been demonstrated as common characteristics of both partial and full-swing shots in golf players of different skill levels and genders using a 3D electromagnetic tracking system (Polhemus Liberty) (Tinmark, Hellström, Halvorsen, \& Thorstensson, 2010). Forty-five golfers (11 male tournament professionals, 21 male and 13 female elite amateurs) performed partial shots with a wedge to targets at three submaximal distances, 40,55 and $70 \mathrm{~m}$, and full-swing shots with a 5 iron and a driver for maximal distance. Pelvis, upper torso and hand movements were recorded at $240 \mathrm{~Hz}$. The magnitude of the resultant angular velocity vector of each segment was computed. 


\section{Wearable sensors}

Another technological advance which has allowed quantification of the biomechanics of the golf swing on the golf course are wearable inertial sensors that contain gyroscopes and triaxial accelerometers. Estimation of the center of mass trajectory is possible using these wearable sensors during golf swings (Najafi, Lee-Eng, Wrobel, \& Goebel, 2015). The accuracy of the system to estimate 3D body segment angles compared to a 3D camera-based motion analyzer was conducted for three golfers and showed relatively high agreement between wearable sensors and the 3D reference for angles $\left(r>0.99\right.$, random error $\left.<1.2^{\circ}=1.5 \%\right)$ for anterior-posterior; $<0.9^{\circ}=2 \%$ for medial-lateral; and $<3.6^{\circ}=2.5 \%$ for internal-external rotation direction). The accuracy of three simplified center of mass trajectory models, conducted for four golfers, showed the two-link model ( $r>0.93)$ had better agreement with the reference system compared to the one-link model $(r=0.52)$. The two-link model estimated center of mass trajectory during multiple golf swings, conducted for 18 golfers, showed relatively good accuracy $(r>0.9$, anterior-posterior random error $<1 \mathrm{~cm}=7.7 \%)$ and $<2 \mathrm{~cm}=10.4 \%)$ for medial-lateral).

Wearable sensors may allow the quantification of 3D motion characteristics of a variety of body segments of golfers and the clubhead in the field.

\section{Summary}

We have highlighted how lab based biomechanical studies of the golf swing using 3D videography, force, electromyography, modelling, and robots, have provided key information regarding the golf swing. With recent advances in technology such as isoinertial devices and wearable sensors, much of this knowledge can now be applied on the golf course. Sports biomechanists are now able to assess and provide relatively real-time feedback on golf swing performance.

\section{References}

Abernethy, B., Neal, R. J., Moran, M. J., \& Parker, A. W. (1990). Expert-novice differences in muscle activity during the golf swing. In A. J. Cochran (Chair), E \& F N Spon. Symposium conducted at the meeting of the Science and Golf I: Proceedings of the First World Scientific Congress of Golf, London.

Alderslade, V., Crous, L. C., \& Louw, Q. A. (2015). Correlation between passive and dynamic range of rotation in lead and trail hips during a golf swing. South African Journal for Research in Sport, Physical Education \& Recreation (SAJR SPER), 37(3), 15-28.

Alexander, D. L., \& Kern, W. (2005). Drive for show and putt for dough?: An analysis of the earnings of PGA tour golfers. Journal of Sports Economics, 6(1), 46-60.

Bačić, B. (2012). Automated assessment of tennis swing performance: Transfer of qualitative analysis to machine learning and back to coaching feedback (PhD). AUT University, Auckland.

Bačić, B., \& Hume, P. A. (2012, May). Augmented video coaching, qualitative analysis and postproduction using open source software. In E. Bradshaw, A. Burnett, \& P. A. Hume (Chair), Australian Catholic University. Symposium conducted at the meeting of the 30th Conference of the International Society of Biomechanics in Sports, Melbourne.

Ball, K. A., \& Best, R. J. (2007a). Different centre of pressure patterns within the golf stroke I: Cluster analysis. Journal of Sports Sciences, 25(7), 757-770.

Ball, K. A., \& Best, R. J. (2007b). Different centre of pressure patterns within the golf stroke II: Groupbased analysis. Journal of Sports Sciences, 25(7), 771-779.

Barrentine, S. W., Fleisig, G. S., Johnson, H., \& Woolley, T. W. (1994). Ground reaction forces and torques of professional and amateur golfers. In M. R. Farrally \& A. J. Cochran (Chair), E \& FN Spon. Symposium conducted at the meeting of the Science and Golf II: Proceedings of the 1994 World Scientific Congress on Golf, London.

Bechler, J. R., Jobe, F. W., Pink, M., Perry, J., \& Ruwe, P. A. (1995). Electromyographic analysis of the hip and knee during the golf swing. Clinical Journal of Sport Medicine, 5, 162-166. 
Bertram, C., \& Guadagnoli, M. A. (2008). The effects of custom-fitted clubs versus "placebo" clubs on golf-swing characteristics. International Journal of Sports Science and Coaching, 3, 93-98.

Betzler, N. F., Monk, S. A., Wallace, E. S., \& Otto, S. R. (2012). Effects of golf shaft stiffness on strain, clubhead presentation and wrist kinematics. Sports Biomechanics, 11(2), 223-238.

Bradshaw, E. J., Keogh, J. W. L., Hume, P. A., Maulder, P., Nortje, J., \& Marnewick, M. (2009). The effect of biological movement variability on the performance of the golf swing in high and low handicapped players. Research Quarterly for Exercise and Sport, 80(2), 185-196.

Brown, S. J., Nevill, A. M., Monk, S. A., Otto, S. R., Selbie, W. S., \& Wallace, E. S. (2011). Determination of the swing technique characteristics and performance outcome relationship in golf driving for low handicap female golfers. Journal of Sports Sciences, 29(14), 1483-1491.

Brown, S. J., Selbie, W. S., \& Wallace, E. S. (2013). The X-Factor: An evaluation of common methods used to analyse major inter-segment kinematics during the golf swing. Journal of Sports Sciences, 31(11), 1156-1163.

Burden, A. M., Grimshaw, P. N., \& Wallace, E. S. (1998). Hip and shoulder rotations during the golf swing of sub 10 handicap players. Journal of Sports Sciences, 16(12), 165-176.

Cheetham, P. J., Martin, P. E., Mottram, R. E., \& St Laurent, B. F. (2001). The importance of stretching the "X-factor" in the downswing of golf: The "X-factor stretch". In P. R. Thomas (Ed.), Optimising Performance in Golf (pp. 192-199). Brisbane: Australian Academic Press.

Cole, M. H., \& Grimshaw, P. N. (2008). Electromyography of the trunk and abdominal muscles in golfers with and without low back pain. Journal of Science and Medicine in Sport, 11(2), 174181.

Cole, M. H., \& Grimshaw, P. N. (2009). The X-factor and its relationship to golfing performance. Journal of Quantitative Analysis in Sports, 5(1), 9.

Cole, M. H., \& Grimshaw, P. N. (2016). The Biomechanics of the Modern Golf Swing: Implications for Lower Back Injuries. Sports Medicine, 46(3), 339-351.

Couceiro, M. S., Dias, G., AraúJo, A., \& Pereira, S. (2015). Inputter: concept and evaluation of an engineered golf putter. South African Journal for Research in Sport, Physical Education \& Recreation (SAJR SPER), 37(3), 43-54.

Delay, D., Nougier, V., Orliaguet, J. P., \& Coello, Y. (1997). Movement control in golf putting. Human Movement Science, 16(5), 597-619.

Delphinus, E. M., \& Sayers, M. G. L. (2012). Putting proficiency: contributions of the pelvis and trunk. Sports Biomechanics, 11(2), 212-222.

Egret, C. I., Nicolle, B., Dujardin, F. H., Weber, J., \& Chollet, D. (2006). Kinematic analysis of the golf swing in men and women experienced golfers. International Journal of Sports Medicine, 27(6), 463-467.

Egret, C. I., Vincent, O., Weber, J., Dujardin, F. H., \& Chollet, D. (2003). Analysis of 3D kinematics concerning three different clubs in golf swing. International Journal of Sports Medicine, 24(6), 465-469.

Evans, K., Horan, S. A., Neal, R. J., Barrett, R. S., \& Mills, P. M. (2012). Repeatability of threedimensional thorax and pelvis kinematics in the golf swing measured using a field-based motion capture system. Sports Biomechanics, 11(2), 262-272.

Evans, K., Refshauge, K. M., Adams, R., \& Barrett, R. (2008). Swing kinematics in skilled male golfers following putting practice. Journal of Orthopaedic and Sports Physical Therapy, 38(7), 425433.

Farber, A. J., Smith, J. S., Kvitne, R. S., Mohr, K. J., \& Shin, S. S. (2009). Electromyographic analysis of forearm muscles in professional and amateur golfers. American Journal of Sports Medicine, 37(2), 396.

Fletcher, I. M., \& Hartwell, M. (2004). Effect of an 8-week combined weights and plyometrics training program on golf drive performance. Journal of Strength and Conditioning Research, 18(1), 59-62. 
Fradkin, A. J., Sherman, C. A., \& Finch, C. F. (2004). How well does club head speed correlate with golf handicaps? Journal of Science and Medicine in Sport, 7(4), 465-472.

Glazebrook, M. A., Curwin, S., Islam, M. N., Kozey, J., \& Stanish, W. D. (1994). An electromyographic analysis and an investigation of intervention strategies. American Journal of Sports Medicine, 22(8), 674-679.

Gryc, T., Zahalka, F., Maly, T., Mala, L., \& Hrasky, P. (2015). Movement's analysis and weight transfer during the golf swing. Journal of Physical Education \& Sport, 15(4), 781-787.

Healy, A., Moran, K. A., Dickson, J., Hurley, C., Smeaton, A. F., O'Connor, N. E., . . Chockalingam, N. (2011). Analysis of the 5 iron golf swing when hitting for maximum distance. Journal of Sports Sciences, 29(10), 1079-1088.

Hellström, J. (2009). Competitive elite golf: A review of the relationships between playing results, technique and physique. Sports Medicine, 39, 723-741.

Horan, S. A., Evans, K., \& Kavanagh, J. J. (2011). Movement variability in the golf swing of male and female skilled golfers. Medicine \& Science in Sports and Exercise, 43(8), 1474-1483.

Horan, S. A., Evans, K., Morris, N. R., \& Kavanagh, J. J. (2010). Thorax and pelvis kinematics during the downswing of male and female skilled golfers. Journal of Biomechanics, 43(8), 1456-1462.

Horan, S. A., Evans, K., Morris, N. R., \& Kavanagh, J. J. (2014). Swing kinematics of male and female skilled golfers following prolonged putting practice. Journal of Sports Sciences, 32(9), 810816.

Horan, S. A., \& Kavanagh, J. J. (2012). The control of upper body segment speed and velocity during the golf swing. Sports Biomechanics, 11(2), 165-174.

Hume, P. A., Keogh, J. W. L., \& Reid, D. (2005). The role of biomechanics in maximising distance and accuracy of golf shots. Sports Medicine, 35(5), 429-449.

Hume, P. A., Reid, D., \& Edwards, T. (2006). Epicondylar injury in sport: Epidemiology, type, mechanisms, assessment, management and prevention. Sports Medicine, 36(2), 151-170.

Jenkins, S. (2008). Weight transfer, golf swing theory and coaching. International Journal of Sports Science and Coaching, 3(0), 29-51.

Joyce, C., Burnett, A., \& Ball, K. (2010). Methodological considerations for the 3D measurement of the X-factor and lower trunk movement in golf. Sports Biomechanics, 9(3), 206-221.

Joyce, C., Burnett, A., Cochrane, J., \& Ball, K. (2013). Three-dimensional trunk kinematics in golf: between-club differences and relationships to clubhead speed. Sports Biomechanics, 12(2), 108-120.

Kao, J., Pink, M., Jobe, F. W., \& Perry, J. (1995). Electromyographic analysis of the scapular muscles during the golf swing. American Journal of Sports Medicine, 23(1), 19-23.

Kawashima, K., Kato, K., \& Miyazaki, M. (2003). Body size and somatotype characteristics of male golfers in Japan. Journal of Sports Medicine and Physical Fitness, 43(3), 334-341.

Kenny, I. C., Wallace, E. S., \& Otto, S. R. (2008). Influence of shaft length on golf driving performance. Sports Biomechanics, 7(3), 322-332.

Keogh, J. W. L., \& Hume, P. A. (2012). Evidence for biomechanics and motor learning research improving golf performance. Sports Biomechanics, 11(2), 288-309.

Keogh, J. W. L., Marnewick, M. C., Maulder, P. S., Nortje, J. P., Hume, P. A., \& Bradshaw, E. J. (2009). Are anthropometric, flexibility, muscular strength, and endurance variables related to clubhead velocity in low- and high-handicap golfers? Journal of Strength and Conditioning Research, 23, 1841-1850.

Keogh, J. W. L., Nortje, J., Maulder, P., Marnewick, M., Hume, P. A., \& Bradshaw, E. (2007, February 15-16). Kinematic predictors of golf swing velocity Symposium conducted the meeting of the 6th Biennial Australia and New Zealand Society of Biomechanics Australasian Biomechanics Conference, University of Auckland. Auckland.

Kummel, J., Kramer, A., \& Gruber, G. (2014). Robotic guidance induces longlasting changes in the movement pattern of a novel sport-specific motor task. Human Movement Science, 38, 2333. 
Kwon, Y. (2010). Kinematic analysis of sports movements: Golf swing plane analysis. presented at the meeting of the XXVIII International Symposium of Biomechanics in Sports, Marquette, $\mathrm{MI}, \mathrm{USA}$.

Kwon, Y., Han, K., Como, C., Lee, S., \& Singhal, K. (2013). Validity of the X-factor computation methods and relationship between the X-factor parameters and clubhead velocity in skilled golfers. Sports Biomechanics, 12(3), 231-246.

Lim, Y.-T., Chow, J. W., \& Chae, W.-S. (2012). Lumbar spinal loads and muscle activity during a golf swing. Sports Biomechanics, 11(2), 197-211.

Lynn, S. K., Frazier, B. S., New, K. N., Wu, W. F. W., Cheetham, P. J., \& Noffal, G. J. (2013). Rotational kinematics of the pelvis during the golf swing: skill level differences and relationship to club and ball impact conditions. International Journal of Golf Science, 2(2), 116-125.

Mackenzie, S. J., \& Evans, D. B. (2010). Validity and reliability of a new method for measuring putting stroke kinematics using the TOMI ${ }^{\circledR}$ system. Journal of Sports Sciences, 28(8), 891-899.

Marshall, R. N., \& McNair, P. J. (2013). Biomechanical risk factors and mechanisms of knee injury in golfers. Sports Biomechanics, 12(3), 221-230.

McHardy, A., \& Pollard, H. (2005). Muscle activity during the golf swing. British Journal of Sports Medicine, 39, 799-804.

McLean, J. (1992). Widen the gap. Golf Magazine, 34(12), 49-53.

McNitt-Gray, J. L., Munaretto, J., Zaferiou, A., Requejo, P. S., \& Flashner, H. (2013). Regulation of reaction forces during the golf swing. Sports Biomechanics, 12(2), 121-131.

McTeigue, M., Lamb, S. R., Mottram, R., \& Pirozzolo, F. (1994). Spine and hip motion analysis during the golf swing. In A. J. Cochran \& M. R. Farrally (Chair), E \& FN Spon. Symposium conducted at the meeting of the Science and Golf II: Proceedings of the 1994 World Scientific Congress of Golf, London.

Meister, D. W., Ladd, A. L., Butler, E. E., Zhao, B., Rogers, A. P., Ray, C. J., \& Rose, J. (2011). Rotational biomechanics of the elite golf swing: Benchmarks for amateurs. Journal of Applied Biomechanics, 27(3), 242-251.

Myers, J., Lephart, S., Tsai, Y.-S., Sell, T., Smoliga, J., \& Jolly, J. (2008). The role of upper torso and pelvis rotation in driving performance during the golf swing. Journal of Sports Sciences, 26(2), $181-188$.

Najafi, B., Lee-Eng, J., Wrobel, J. S., \& Goebel, R. (2015). Estimation of center of mass trajectory using wearable sensors during golf swing. Journal of Sports Science \& Medicine, 14(2), 354-363.

Neal, R. J., \& Wilson, B. D. (1985). 3D kinematics and kinetics of the golf swing. International Journal of Sport Biomechanics, 1, 221-232.

Nesbit, S. M. (2005a). A three dimensional kinematic and kinetic study of the golf swing. Journal of Sports Science and Medicine, 4, 499-519.

Nesbit, S. M. (2005b). Work and power analysis of the golf swing. Journal of Sports Science and Medicine, 4, 520-533.

Nesbit, S. M., \& McGinnis, R. S. (2014). Kinetic constrained optimization of the golf swing hub path. Journal of Sports Science \& Medicine, 13(4), 859-873.

Oliver, M. H., Horan, S. A., Evans, K. A., \& Keogh, J. W. L. (2016). The effect of a seven-week exercise program on golf swing performance and musculoskeletal measures. International Journal of Sports Science and Coaching, 11(4), 610-618. doi:10.1177/1747954116654784

Reinkensmeyer, D. J., \& Patton, J. L. (2009). Can robots help the learning of skilled actions? Exercise and Sport Sciences Reviews, 37(1), 43-51.

Robertson, S. J., Burnett, A. F., Newton, R. U., \& al., e. (2012). Development of the nine-ball skills test to discriminate elite and high-level amateur golfers. J Sports Sci, 30, 431-437.

Robinson, R. L. (1994). A study of the correlation between swing characteristics and club head velocity. In A. J. Cochran \& M. R. Farrally (Chair), E \& FN Spon. Symposium conducted the meeting of the Science and Golf II: Proceedings of the 1994 World Scientific Congress of Golf, London. 
Smith, A. C., Roberts, J. R., Wallace, E. S., Pui, K., \& Forrester, S. E. (2016). Two- and threedimensional methods have been used for analysis of trunk kinematic variables in the golf swing. Journal of Applied Biomechanics, 32(1), 23-31.

Sprigings, E. J., \& Mackenzie, S. J. (2002). Examining the delayed release in the golf swing using computer simulation. Sports Engineering (International Sports Engineering Association), 5(1), 23-32.

Sprigings, E. J., \& Neal, R. J. (2000). An insight into the importance of wrist torque in driving the golf ball: A simulation study. Journal of Applied Biomechanics, 16(4), 356-366.

Stastny, P., Maszczyk, A., Tománková, K., Kubový, P., Richtrová, M., Otáhal, J., . . . Cięszczyk, P. (2015). Kinetic and kinematic differences in a golf swing in one and both lower limb amputees Journal of Human Kinetics, 48(1), 33-41.

Sweeney, M., Mills, P., Alderson, J., \& Elliott, B. (2013). The influence of club-head kinematics on early ball flight characteristics in the golf drive. Sports Biomechanics, 12(3), 247-258.

Tinmark, F., Hellström, J., Halvorsen, K., \& Thorstensson, A. (2010). Elite golfers' kinematic sequence in full-swing and partial-swing shots. Sports Biomechanics, 9(4), 236-244.

Torres-Ronda, L., Delextrat, A., \& Gonzalez-Badillo, J. J. (2014). The relationship between physical and fitness requirements in elite golf performance. International SportMed, 15(2), 156-164.

Wallace, E. S., Otto, S. R., \& Nevill, A. (2007). Ball launch conditions for skilled golfers using drivers of different lengths in an indoor testing facility. Journal of Sports Sciences, 25(7), 731-737.

Watkins, R. G., Uppal, G. S., Perry, J., Pink, M., \& Dinsay, J. M. (1996). Dynamic electromyographic analysis of trunk musculature in professional golfers. American Journal of Sports Medicine, 24(4), 535-538.

Wheat, J. S., Vernon, T., \& Milner, C. E. (2007). The measurement of upper body alignment during the golf drive. Journal of Sports Sciences, 25(7), 749-755.

Williams, K. R., \& Sih, B. L. (2002). Changes in golf clubface orientation following impact with the ball. Sports Engineering (International Sports Engineering Association), 5(2), 65-80.

Worobets, J., \& Stefanyshyn, D. (2012). The influence of golf club shaft stiffness on clubhead kinematics at ball impact. Sports Biomechanics, 11(2), 239-248.

Worsfold, P., Smith, N. A., \& Dyson, R. J. (2008). Low handicap golfers generate more torque at the shoe-natural grass interface when using a driver. Journal of Sports Science and Medicine, 7(3), 408-414.

Zheng, N., Barrentine, S. W., Fleisig, G. S., \& Andrews, J. R. (2008). Swing kinematics for male and female pro golfers. International Journal of Sports Medicine, 29, 965-970.

\section{Index}

2D video analysis, 4

3D motion, 6

asymmetrical motion, 2

backswing time, 4

centre of pressure, 4

clubhead velocity, 3

clubs, 7

coordination, 4

coupling, 5

disability, 8

downswing, 4

downswing amplitude, 3

electromagnetic tracking, 11

Electromyography, 9

flexibility, 6 gender, 8

Golf, 2

grip strength, 4

ground reaction forces, 8

kinetic, 8

low handicap, 4

models, 9

muscle activity, 9

outcome measures, 3

pelvic rotations, 6

pelvis kinematics, 5

pelvis translation, 4

pelvis-thorax differential, 4

power, 3

radar gun, 3 
Robots, 11

Shaft length, 7

shaft stiffness, 7

shoulder flexion, 7

sitting flexibility, 4

trunk kinematic, 7 wearable inertial sensors, 11

weight transfer, 8

wrists, 10

$X$-factor, 5

$\mathrm{X}$-factor stretch, 4

\section{Cross references}

Related chapters to this chapter.

Estimation of the Body Segment Inertial Parameters for the Rigid Body Biomechanical Models Used in Motion Analysis

Rigid Body Models of the Musculoskeletal System

Arthrokinematics and Joint Morphology

3D Dynamic Pose Estimation Using Reflective Markers or Electromagnetic Sensors

3D Dynamic Pose Estimation Using Wearable Robotics

3D Muscle, Ligament and Tendon Motion Using Ultrasound

3D Dynamic Probablistic Pose Estimation Using Cameras and Reflective Markers.

3D Dynamic Pose Estimation Using Surface Parameterization (MoSh)

3D Dynamic Pose Estimation Using Cameras and No Markers

3D Dynamic Pose Estimation Using Inertial Measurement Units.

Gait Parameters Estimated Using Inertial Measurement Units

A Physics-based Statistical Model for Human Gait Analysis

3D Kinematics of Human Motion

Simulation of Soft Tissue Loading That Generates Observed Movement Dynamics

Induced Acceleration and Induced Power Analyses

Pressure Platforms

Optimal Control Strategies for Human Movement

Time Series Analysis/Time Series Processing of Signals

Frequency Analysis/Wavelet Analysis

Machine Learning Techiques for Data Analytics of Human Motion

Data Analytics for Biomechanics

Normalization Techniques

Surface EMG

Clinical Gait Assessment by Video Observation and 2D-Techniques

Conventional Gait Model - Success and Limitations

Variations of Marker-sets and Models for Standard Gait Analysis

Next Generation Models Using Optimized Joint Center Location

Kinematic Foot Models for Instrumented Gait Analyis

Trunk and Spine Models for Instrumented Gait Analyis

Upper Extremity Models for Clinical Movement Analysis

Interpreting Ground Reaction Forces in Gait

Interpreting Joint Moments and Powers in Gait

Functional Effects of Foot Orthoses

Functional Effects of Shoes

The Movement of Scull and Oar Rowing

Segmental Movements in Cycling

Movement Analysis of the Golf Swing 